\title{
Different concentrations of Chinese medicine Xiaoyingdaotan Decoction on Hashimoto's thyroiditis mouse model
}

\section{Yingjia Zhou}

Yunnan Cancer Hospital https://orcid.org/0000-0001-8049-567X

Hongmei Shen

Yunnan Cancer Hospital

Weibo Wen ( $\nabla$ zxbzyjzmy@163.com )

Yunnan Provincial Hospital of Chinese Medicine

\section{Research}

Keywords: Different concentrations, Xiaoyingdaotan Decoction, Hashimoto's thyroiditis, Notch/Treg/Th17 pathway, animal experiment

Posted Date: November 8th, 2021

DOI: https://doi.org/10.21203/rs.3.rs-1013029/v1

License: (9) This work is licensed under a Creative Commons Attribution 4.0 International License. Read Full License 


\section{Abstract \\ Background}

Through the detection of Notch/Treg/Th17 pathway related factors, to explore the effect of different concentrations of Chinese medicine Xiaoyingdaotan Decoction on Hashimoto's thyroiditis mouse model.

\section{Methods}

To make the mouse model of Hashimoto's thyroiditis, and to administer the Chinese medicine Xiaoyingdaotan Decoction of different concentrations by gavage. After the treatment, the expression of serum Notch protein and Treg/Th17 cytokine levels in mice were detected. The quantitative data conformed to the normal distribution with $\mathrm{t}$ test, and did not conform to the normal distribution with Wilcoxon rank sum test.

\section{Results}

The serum Notch protein expression of mice in the model group was significantly higher than that of the other groups, and the difference was statistically significant $(P<0.001)$. Comparing the high-dose Chinese medicine group with the low-dose Chinese medicine group and the model group, the level of the key activation protein FOX-P3 in serum of Treg cells in mice was significantly increased, and the difference was statistically significant $(P<0.05)$. Compared with the model group, the serum TGF- $\beta$ levels of each group of traditional Chinese medicine were significantly higher than that of the model group, and the difference was statistically significant $(P<0.05)$. The levels of key activating proteins STAT3, RORYt and IL-22 in serum of Th17 cells in each group of traditional Chinese medicine mice were significantly lower than those in the model group, with statistical differences $(P<0.05)$.

\section{Conclusion}

Different concentrations of Chinese medicine Xiaoyingdaotan Decoction can down-regulate the expression of Notch protein in HT mouse model, and can effectively regulate Treg/Th17 cytokines.

\section{Impact Statement}

For HT patients with subclinical hypothyroidism, about $5 \%$ of recessive patients develop overt hypothyroidism every year, requiring life-long treatment with thyroid hormones. However, thyroid hormone replacement therapy can only improve the patient's thyroid function, reduce the uncomfortable symptoms caused by abnormal thyroid function, and make the thyroid volume smaller, but it cannot improve the inflammatory state and autoimmune response caused by Hashimoto's thyroiditis, and there is no way to prevent the occurrence of hypothyroidism early. Traditional Chinese medicine has many researches on 
the treatment of this disease due to its advantages of convenience and low price, low side effects, "preventing the disease" and individualized syndrome differentiation and treatment. However, most of them are for improving the clinical symptoms of patients, and it is rarely studied on the molecular level from animal experiments.

\section{Introduction}

Hashimoto's thyroiditis (HT) was first described by Dr. Hashimoto Hakaru of Japan in 1912, and so named. The onset of HT is insidious. The patients may have no obvious symptoms such as neck compression and pain in the early stage, but they often feel fatigue and discomfort. Some HT patients may also have autoimmune diseases such as type 1 diabetes $^{[1]}$, Sjogren's syndrome ${ }^{[2]}$, Polycystic Ovary Syndrome ${ }^{[3]}$, Psoriasis ${ }^{[4]}$, Multiple Sclerosis ${ }^{[5]}$, and idiopathic thrombocytopenic purpura ${ }^{[6]}$. HT has a long course and slow progress. The thyroid gland can gradually increase with the course of the disease. Thyroid reserve capacity continues to decrease, and thyroid tissue is constantly damaged. When it reaches a certain level, hypothyroidism gradually appears.

Many scholars have carried out experimental studies and believe that the Notch signaling pathway can mediate immune inflammatory response by regulating the levels of Regulatory $T$ cells(Treg)/T helper cell 17(Th17) cytokines, thereby participating in a variety of autoimmune diseases and inflammatory diseases $^{[7-10]}$. HT is considered to be the first disease of autoimmune origin. Therefore, Notch protein may also promote the occurrence and development of HT by affecting the levels of Treg/Th17 cytokines. In order to confirm this conclusion, we created a mouse model of Hashimoto's thyroiditis, used different concentrations of Chinese medicine Xiaoyingdaotan Decoction to gavage the mice, and explored the differences by detecting the expression of Notch protein and Treg/Th17 cytokines in the serum of mice. To explore the effect of different concentrations of traditional Chinese medicine on mice, and to explore whether the Notch protein pathway is involved in the pathogenesis of HT by affecting the Treg/Th17 cell axis.

\section{Materials And Methods}

\subsection{Experimental animals and groups}

The animal experiment was approved by the Animal Experiment Department of Kunming Medical University. Select $40 \mathrm{CBA} / \mathrm{J}$ female mice, weighing $18-20 \mathrm{~g}$. Forty CBA/J mice were randomly divided into 4 groups, namely the model group and the low, medium and high dose groups of Xiaoyingdaotan Decoction, with 10 mice in each group.

\subsection{Main drugs}

Chinese medicine Xiaoyingdaotan Decoction Medicine composition: Prunella vulgaris $30 \mathrm{~g}$, Fritillaria $15 \mathrm{~g}$, Bupleurum 10g, Oyster 30g, Panshanlong 30g, Deer horn cream 30g, Turmeric 15g, Roasted xiangfu 15g, Angelica $15 \mathrm{~g}$, White peony $30 \mathrm{~g}$, Chuanxiong $15 \mathrm{~g}$, Licorice $10 \mathrm{~g}$. 


\subsection{Experimental method}

\subsubsection{Modeling method}

Dissolve powdered porcine thyroglobulin (PTg) in a PBS solution and mix it with the same volume of Freund's complete adjuvant (CAF), fully emulsify it, and inject PTg $100 \mu \mathrm{g} / \mathrm{mouse}$ subcutaneously into the foot pad and back of the mouse. Once a week for 2 consecutive weeks. Boost immunization: start boost immunization at the 4th week, mix PTg with the same volume of Incomplete Freund's Adjuvant (IAF), and after fully emulsify, use the same method to inject PTg $100 \mu \mathrm{g} /$ mouse into the mouse's footpads and back subcutaneously at multiple points again, once a week for 4 consecutive weeks ${ }^{[11]}$.

\subsubsection{Method of administration}

After successful modeling, mice in the model group were given saline $0.1 \mathrm{ml} / 10 \mathrm{~g}$ by gavage. The dose of traditional Chinese medicine was calculated according to the maximum dose taken by humans and the body surface area of mice. The conversion relationship between $20 \mathrm{~g}$ mouse and $70 \mathrm{KG}$ human was 0.0026:1. One dose of Chinese medicine Xiaoyingdaotan Decoction was added with $500 \mathrm{ml}$ of water, and the drug solution was $300 \mathrm{ml}$ after decoction. The drug solution was heated and concentrated to $100 \mathrm{ml}$ to prepare the drug solution for later use. The low-dose group was diluted with distilled water for 1 time and the drug solution was administered at $0.1 \mathrm{ml} / 10 \mathrm{~g} \cdot \mathrm{d}$, the middle-dose group was administered with the drug solution $0.1 \mathrm{ml} / 10 \mathrm{~g} \cdot \mathrm{d}$, the drug solution was heated and concentrated by 1 time in the high-dose group and then administered at $0.1 \mathrm{ml} / 10 \mathrm{~g} \cdot \mathrm{d}$. Each group was administered once a day for 6 weeks.

\subsubsection{Detection Indicator}

هMouse serum Notch protein expression detection: ELISA method was used to detect the serum Notch protein expression of mice in each group.

$\triangle$ Detection of serum Treg cell-related transcription factor levels in mice: ELISA was used to detect the levels of key Treg activation proteins FOX-P3, TGF- $\beta$, and IL-10 in each group of mice.

QDetection of serum Th17 cell-related transcription factor levels in mice: ELISA was used to detect the levels of key activating proteins STAT3, RORyt, IL-17 and IL-22 in serum of Th17 cells in each group.

\subsection{Statistical analysis}

Quantitative indicators were described in terms of mean \pm standard deviation. The quantitative data conformed to the normal distribution with $\mathrm{t}$ test, and did not conform to the normal distribution with Wilcoxon rank sum test. The hypothesis test uses a two-sided test uniformly, and the test statistics and the corresponding $P$ value are given. $P \leq 0.05$ as the difference is statistically significant, and $P \leq 0.01$ as the difference is statistically significant.

\section{Results}




\subsection{Comparison of serum Notch protein expression of mice in each group}

It can be seen from Table. 1 that the serum Notch protein expression between the 4 groups of mice was compared in pairs. The serum Notch protein expression of mice in the model group was significantly higher than that of the other groups, and the difference was significant $(P<0.001)$; In addition, the other groups were compared in pairs, and the difference was not statistically significant $(P>0.05)$.

It can be seen from Figure.1 that compared with the model group, the expression of Notch protein in the other groups was significantly reduced, and the difference was statistically significant $(P<0.001)$.

\subsection{Comparison of key activation protein levels of serum Treg cells in each group of mice}

It can be seen from Table.2 that the four groups of mice serum Treg cell key activation protein FOX-P3 levels were compared in pairs. There were statistical differences between the high-dose Chinese medicine group and the low-dose Chinese medicine group, the model group $(P<0.05)$. The serum TGF- $\beta$ levels of the 4 groups of mice were compared in pairs, and the difference was statistically significant between the model group and the high, medium, and low dose groups of Chinese medicine $(P<0.05)$. There was no statistically significant difference in serum IL-10 levels between the 4 groups of mice $(P>0.05)$.

It can be seen from Figure.2 that the serum FOX-P3 level of mice in the high-dose Chinese medicine group was significantly higher than that of the low-dose Chinese medicine group and the model group, and the difference was statistically significant $(P<0.05)$.

It can be seen from Figure. 3 that compared with the model group, the serum TGF- $\beta$ level of the three groups of traditional Chinese medicine was significantly higher than that of the model group, and the difference was statistically significant $(P<0.05)$.

It can be seen from Figure.4 that there was no statistical difference in the serum IL-10 levels of mice in each group ( $P>0.05)$. Compared with the model group, the serum IL-10 levels of mice in the other groups had a downward trend, but the difference was not statistically significant.

\subsection{Comparison of key activating protein levels of Th17 cells in serum of mice in each group}

It can be seen from Table. 3 that the 4 groups of mice serum Th17 cell key activation protein STAT3, RORyt, IL-22 levels were compared in pairs, compared with the model group and the other three groups, there were statistical differences $(P<0.05)$. There was no significant difference in serum IL-17 levels among the 4 groups of mice ( $P>0.05)$.

It can be seen from Figures. 5 that compared with the model group, the serum STAT3 levels of mice in the 3 groups of traditional Chinese medicine decreased significantly, with statistical differences $(P<0.05)$. 
It can be seen from Figures. 6 that compared with the model group, the serum RORyt levels of mice in the 3 groups of traditional Chinese medicine decreased significantly, with statistical differences $(P<0.05)$.

It can be seen from Figures.7 that compared with the model group, the serum IL-22 levels of mice in the 3 groups of traditional Chinese medicine decreased significantly, with statistical differences $(P<0.05)$.

It can be seen from Figure. 8 that there was no statistical difference in the serum IL-17 levels of mice in each group ( $P>0.05$ ). Compared with the model group, the serum IL-17 levels of mice in the other groups had a downward trend, but the difference was not statistically significant.

\section{Discussion}

\subsection{Establishment of a mouse model of Hashimoto's thyroiditis}

In clinical practice, because there are not many patients with Hashimoto's thyroiditis that require surgical treatment, and thyroid tissue is not easy to obtain, the research on the mechanism of Xiaoyingdaotan Decoction from the human body cannot be further in-depth, so while clinical observation of patients, choose In vivo studies of animals can increase persuasiveness. Rats are commonly used animals for autoimmune thyroiditis models. At present, thyroglobulin ( $\mathrm{Tg}$ ) combined with Freund's adjuvant or highiodine water is commonly used in the world for experimental animal modeling. CBA/J mice are usually used to establish animal models. At the same time, because female rats are more likely to induce Hashimoto's thyroiditis, female CBA/J mice were selected as the research objects to detect the changes in the levels of Notch protein, Treg, Th17 and other cytokines before and after treatment with traditional Chinese medicine.

\subsection{Protective Effect of Xiaoyingdaotan Decoction on HT Mouse Model}

\subsubsection{Effect of Xiaoyingdaotan Decoction on Notch Protein Expression in HT Mouse Model}

The results of the study showed that the serum Notch protein expression between the 4 groups of mice was compared in pairs. Compared with the model group of mice, the Notch protein expression of the remaining groups was significantly decreased, and the differences were statistically significant. It showed that different doses of Chinese medicine Xiaoyingdaotan Decoction could effectively down-regulate the expression level of Notch protein.

\subsubsection{Effect of Xiaoyingdaotan Decoction on Key Activated Protein Levels of Treg Cells in HT Mouse Model}

By analyzing and comparing the levels of key activating proteins FOX-P3, TGF- $\beta$ and IL-10 in serum of each group of mice, the results showed that the serum FOX-P3 level of mice in the high-dose group of Chinese medicine was compared with that of the low-dose group and model of traditional Chinese 
medicine. There are statistical differences between the groups. It showed that the high-dose concentration of Chinese medicine Xiaoyingdaotan Decoction was more effective to up-regulate the serum FOX-P3 level in the HT mouse model compared with the lower-dose concentration of Chinese medicine. Compared with the model group, the serum TGF- $\beta$ levels of mice in each group of Chinese medicine were significantly increased, indicating that different doses of Chinese medicine Xiaoyingdaotan Decoction could effectively up-regulate the serum TGF- $\beta$ level of HT mouse models. There was no significant statistical difference in serum IL-10 levels between each group of mice, indicating that the Chinese medicine Xiaoyingdaotan Decoction could not effectively up-regulate the serum IL-10 levels in HT mouse models.

\subsubsection{Effect of Xiaoyingdaotan Decoction on Key Activated Protein Levels of Th17 Cells in HT Mouse Model}

By analyzing and comparing the levels of key activating proteins STAT3, RORYt and IL-22 in serum of Th17 cells in each group of mice, the results of the study showed that serum STAT3, RORYt and IL-22 levels of HT mouse models in each group of Chinese medicine were significantly lower than those in the model group. It showed that different doses of Chinese medicine Xiaoyingdaotan Decoction could effectively down-regulate the serum STAT3, RORyt and IL-22 levels in HT mouse models. There was no significant difference in serum IL-17 levels between the 4 groups of mice. From the results of the study, serum IL-17 levels of HT mouse models in each group of Chinese medicine had a downward trend compared with the model group, but there was no statistical difference in this decline. It showed that Xiaoyingdaotan Decoction could not effectively down-regulate the level of serum IL-17 in HT mouse models.

The maturation of T cells in the thymus is a highly dynamic process that includes discrete steps of lineage typing, T cell receptor (TCR) rearrangement and selection, which are related to the proliferation, survival and mortality of various $T$ cell subpopulations Related ${ }^{[12]} \cdot \mathrm{CD}^{+} \mathrm{T}$ cells can express $\mathrm{CD} 8$ glycoprotein and can recognize their target cells by binding to major histocompatibility complex (MHC) class I antigens ${ }^{[13]}$. CD $4^{+} \mathrm{T}$ cells can be further divided into various subtypes by their secreted cytokines and specific transcription factors, such as Th1, Th2, Th17, Th22, Tfh and Treg ${ }^{[14]}$. With the deepening of research, more and more studies have revealed the pathogenic role of Th17 and IL-17 in immune response and autoimmune diseases, and found that Th17 cells play a more important role in the pathogenesis of $\mathrm{HT}^{[15,16]}$. Natural Treg derived from the thymus can secrete IL-35. IL-35 is an important anti-inflammatory factor that can induce the proliferation of Treg cells and produce FOX- P3 and reduce the progression of inflammatory diseases ${ }^{[17]}$. The function of Treg cells depends on the expression of FOX-P3, and mainly exerts an immunosuppressive effect.

Some scholars compared AITD patients with healthy subjects, and found that the mRNA expression of Th17 and its transcription factor RORyt in the peripheral blood of AITD patients was higher than that of the healthy control group $(P<0.05)$, especially in the HT subgroup $(P<0.01)$, while the expression level of Treg cells and its transcription factor FOX-P3 mRNA was significantly reduced $(P<0.05)^{[18]}$. Similarly, 
some scholars have tested the ratio of Treg and Th17 cells in PBMCs of HT patients and healthy subjects, and found that the ratio of Treg/Th17 in the HT group was significantly positively correlated with serum TPOAb and TgAb titers. It showed that the imbalance of Treg/Th17 cell axis may be involved in the autoimmune damage of $\mathrm{HT}$, and it is positively correlated with thyroid autoantibody titer.

According to research reports, the Notch signaling pathway is involved in the pathogenesis of many autoimmune diseases by affecting the balance of Treg/Th17 cells. Some scholars reported that the Notch signaling pathway is involved in the pathogenesis of patients with preeclampsia by maintaining the balance of Treg/Th17 cells ${ }^{[19]}$. Some scholars reported that the Notch1 signaling pathway is involved in the pathogenesis of psoriasis vulgaris patients by regulating the immune imbalance of Treg/Th17[20] Some scholars ${ }^{[21]}$ reported that Notch/RBP-J/FOX-P3/RORyt pathway can play a role in the development of aplastic anemia patients by regulating the balance of Treg/Th17. In addition, Notch signaling regulates the Treg/Th17 cell axis and is also involved in immune thrombocytopenia ${ }^{[22]}$, chronic hepatitis $\mathrm{C}^{[23]}$, allergic asthma ${ }^{[24]}$, autoimmune uveitis ${ }^{[25]}$, rheumatoid arthritis ${ }^{[26,27]}$ and other autoimmune diseases. Therefore, Notch signaling pathway may also participate in the pathogenesis of HT by affecting the balance of Treg/Th17 cells. Through animal experiments, we did observe the changes of Notch protein and the key activation protein of Treg/Th17 cells in the serum of HT mouse model, thus confirming this inference.

In general, the Chinese medicine Xiaoyingdaotan Decoction of different doses and concentrations could effectively down-regulate the serum Notch protein expression level in HT model mice; it could effectively up-regulate the key activation protein levels of mouse serum Treg cells. Relatively speaking, high-dose concentration of Chinese medicine Xiaoyingdaotan Decoction could effectively increase the level of serum FOX-P3 in mice; Chinese medicine Xiaoyingdaotan Decoction of different concentrations could be effective in mice serum Th17 cell key activation protein levels. Studies have confirmed that Notch protein could participate in the pathogenesis of HT by regulating Treg/Th17 cytokines, and has different expression levels in HT mouse models. Although the Chinese medicine Xiaoyingdaotan Decoction could regulate the Notch/Treg/Th17 pathway, studies have found that different concentrations of Chinese medicines could play a regulatory role, and there was no significant difference in this regulatory role.

\section{Conclusion}

Different concentrations of Chinese medicine Xiaoyingdaotan Decoction can down-regulate the expression of Notch protein in HT mouse model, and can effectively regulate Treg/Th17 cytokines.

\section{Abbreviations}

CAF Freund's complete adjuvant

HT Hashimoto's thyroiditis 
IAF Incomplete Freund's Adjuvant

PTg porcine thyroglobulin

$\mathrm{Tg} \quad$ thyroglobulin

Th17 Thelper cell 17

Treg Regulatory T cells

\section{Declarations}

\section{Ethical Approval and Consent to participate:}

The study had been approved by the responsible IRB(Ethics Review Committee of Kunming Medical University, approval number: 2020-85) and that informed consent was obtained from research subjects.

\section{Consent for publication:}

We declare that this manuscript is original, has not been published before and is not currently being considered for publication elsewhere. We confirm that the manuscript has been read and approved by all named authors and that there are no other persons who satisfied the criteria for authorship but are not listed. We further confirm that the order of authors listed in the manuscript has been approved by all of us.

\section{Availability of supporting data:}

All data and models generated or used during the study appear in the submitted article.

\section{Competing interests:}

The authors declared no potential conflicts of interest with respect to the research, authorship, and/or publication of this article.

\section{Funding:}

The authors disclosed receipt of the following financial support for the research, authorship, and/or publication of this article: This work was supported by the Special Project of Ministry of Science and Technology Guiding Local Science and Technology Development, Scientific Research Fund Project of Yunnan Education Department (2018JS224), and National Training Program for Innovative Talents of Traditional Chinese Medicine (CZO099).

\section{Authors' Contributions:}


All authors participated in the design, interpretation of the studies and analysis of the data and review of the manuscript; ZYJ and SHM conducted the experiments, WWB supplied critical reagents and mice, ZYJ and SHM wrote the manuscript, and WWB's contribution was to revise the article and improve the statistical analysis work.

\section{Acknowledgements:}

We are very grateful to Dr. Yao Qian for his help and guidance during the animal experiment, and thank him for patiently guiding us to gavage the experimental mice with Chinese medicine to ensure that the animal experiment can be completed smoothly.

\section{References}

1. Katerina S, Lenka M, Krzysztof U, Miroslav V, Simona H, Milan K, Zlatko P. Sexual Dysfunction in Women Treated for Type 1 Diabetes and the Impact of Coexisting Thyroid Disease. Sex Med, 2019, 7(2): 217-226.

2. Mingmin S, Lei C. Sjögren's syndrome complicated with Fanconi syndrome and Hashimoto's thyroiditis: Case report and literature review. J Int Med Res, 2016, 44(3): 753-759.

3. Natalia L, Ewan H. Genetic Susceptibility to Joint Occurrence of Polycystic Ovary Syndrome and Hashimoto's Thyroiditis: How Far Is Our Understanding? Front Immunol, 2021, 12: 1-24.

4. Haider A, Khalil H, Abbas M. Is There Any Association Between Psoriasis and Hashimoto's Thyroiditis? Cureus, 2019, 11(3):4269-4284.

5. Simona P, Serena M, Francesca M, Ilaria G, Michela S, Gabriele B, Stefania C, llaria M, Giancarlo P, Fabio O, Antonio B. The Footprints of Poly-Autoimmunity: Evidence for Common Biological Factors Involved in Multiple Sclerosis and Hashimoto's Thyroiditis. Front Immunol, 2018, 9: 311-323.

6. Hassan T, Faizan S, Jahnavi S, Vistasp D. Immune Thrombocytopenia (ITP) Secondary to Subclinical Hashimoto's Thyroiditis: Role of Levothyroxine in Improving the Clinical Outcome of ITP. J Investig Med High Impact Case Rep, 2016, 4(2): 1-4.

7. Seyyed A. Targeting cell signaling in allergic asthma. Signal Transduct Target Ther, 2019,10(4): 4564.

8. Wang Z, Kazunori K, Masao H, Shinichi H, Takayoshi S, Hikari O, Noriaki O, Tetsuro S, Taro Y, Yoshio S, Eishiro M, Seishi M, Shuichi K. Notch signaling facilitates hepatitis B virus covalently closed circular DNA transcription via cAMP response element-binding protein with E3 ubiquitin ligasemodulation. Sci Rep, 2019,9(1):1621-1633.

9. Hani H, Emmanuel S, Elena C, Mehdi B, Amir M, Ye C, Louis C, Sena A, Safa B, Amparito C, Juan C, Raif G, Amirhosein M, Boris G, Klaus A, Constantinos S, Wanda P, Talal C. A regulatory T cell Notch4GDF15 axis licenses tissue inflammation in asthma. Nat Immunol, 2020,21(11): 1359-1370.

10. Chuang Z, Xiaoyan L, Yan Y, Zunyuan L, Miao L, Qian T, Wei L, Zhidan L. An analysis of Treg/Th17 cells imbalance associated microRNA networks regulated by moxibustion therapy on Zusanli (ST36) 
and Shenshu (BL23) in mice with collagen induced arthritis. Am J Transl Res, 2019,11(7): 40294045.

11. Ana V, Carmen G. Selenoproteins in human body: focus on thyroid pathophysiology. Hormones (Athens), 2018,17(2):183-196.

12. Eleni V, Alix P, Armin S, Elisabeth M, Wilhelm G. Deoxynivalenol Affects Proliferation and Expression of Activation-Related Molecules in Major Porcine T-Cell Subsets. Toxins (Basel), 2019,11(11): 644665.

13. Alessandra P, Femke W. CD8(+) T cells in human autoimmune arthritis: The unusual suspects. Nature Reviews Rheumatology, 2016,12(7):421-428.

14. Lu C, Bing G, Francesco C, Louella V, Tony K, Diego M, Stephen W, Ying Y, Kousik K, Simone E, Avik D, David R, Frances B, Daniel M, Alice M, Jose F, Sophia R, Steven W, Samantha F, Xiaojian S, John L, Adriana R, Cornelis A, Vyacheslav A, Sofie A, Kim B, Lorenzo B, Guillaume B, David B, Stephan B, Maxime C, Shuhuang C, Warren C, Oliver D, Emmanouil D, Heather E, Irina C, Frederik B, Paul F, Ehsan H, Valentina I, Eva M, Bowon K, Hans L, Ernesto L, Amit M, Filomena M, Matthew M, John M, Vera P, Farzin P, Karola R, Augusto R, Thomas R, Nilofar S, Marie S, Marc S, Alfonso V, Klaudia W, Shuangyin W, Mattia F, Stylianos A, Laura C, Marie Y, Stephan B, Roderic G, Daniel R, Joost M, Willem O, Taco K, Dirk P, Hendrik S, Oliver S, Kate D, Tomi P, Nicole S. Genetic drivers of epigenetic and transcriptional variation in human immune cells. Cell, 2016,167(5):1398-1414.

15. Hanaa E, Huda F, Mona T, Hanaa A. Improving Hashimoto's thyroiditis by eradicating Blastocystis hominis: Relation to IL-17[J]. Ther Adv Endocrinol Metab, 2020,2(11): 1-8.

16. Ceyla D, Banu Y, Fusun T, Ayse K, Ozlem I, Isıl F, Emine Y, Nuri C, Semra K, Metin A. Circulating Th17 cytokine levels are altered in Hashimoto's thyroiditis[J]. Cytokine, 2016,80:13-17.

17. Xinyuan L, Pu F, Yu S, Ying S, William Y, Xiaohua J, Hong W, Xiaofeng Y. Anti-inflammatory cytokines IL-35 and IL-10 block atherogenic lysophosphatidylcholine-induced, mitochondrial ROS-mediated innate immune activation, but spare innate immune memory signature in endothelial cells. Redox Biol, 2020,1(28): 1373-1382.

18. Li C, Yuan J, Zhu Y, Yang X, Wang Q, Xu J, He S, Zhang J. Imbalance of Th17/Treg in Different Subtypes of Autoimmune Thyroid Diseases. Cellular Physiology \& Biochemistry International Journal of Experimental Cellular Physiology Biochemistry \& Pharmacology, 2016,40(1-2):245-252.

19. Atefeh B, Bahia N, Mohammad A, Moslem A, Mahsa H, Behrouz G. Evaluation of IL-17 and IL-35 Serum Levels in Patients with Preeclampsia. J Reprod Infertil, 2019,20(4): 237-243.

20. Lei M, HaiBo X, Tianqin G, MeiLan G, YuJie Z. Notch1 Signaling Regulates the Th17/Treg Immune Imbalance in Patients with Psoriasis Vulgaris. Mediators of Inflammation, 2018,1(3):1-10.

21. Hongbo L, Lin W, Yan P, Zujun J, Zenghui L, Haowen X, Haijia C, Xiaohu G, Hai L, Yang X. In patients with chronic aplastic anemia, bone marrow-derived MSCs regulate the Treg/Th17 balance by influencing the Notch/RBP-J/FOXP3/RORyt pathway. Sci Rep, 2017,7:2488-2498.

22. Jianqin $L$, Jianmei T, Xiaoru F, Zhaoyue W, Jing L, Xiaofang W, Feiyun Y, Yalin X. miR-106b-5p induces immune imbalance of Treg/Th17 in immune thrombocytopenic purpura through 
NR4A3/Foxp3 pathway. Cell Cycle, 2020,19(11): 1265-1274.

23. Qin L, Zhou C, Wu J, Zhuo Y, Wang P, Si Y, Qin M. Notch signaling modulates the balance of regulatory T cells and T helper 17 cells in patients with chronic hepatitis C. DNA and Cell Biology, 2017,1(36):311-320.

24. Changchong L,Anqun S,Xiaoxiao J,Zeyu Z,Xueya Z,Wei Z,Xi W. Th17/Treg dysregulation in allergic asthmatic children is associated with elevated notch expression. Journal of Asthma Official Journal of the Association for the Care of Asthma, 2016,137(2):1-7.

25. Yuxi C, Zhuang L, He L, Wenru S, Yanyan X, Yuan P, Xiaoqing C, Dan L. Apremilast Regulates the Teff/Treg Balance to Ameliorate Uveitis via PI3K/AKT/Fox01 Signaling Pathway. Front Immunol, 2020,11: 1-11.

26. Shengwei J, Siyuan S, Hanzhi L, Jinglan M, Xu Z, Zhen X, Ning Z, Wen J, Yu S, Liu C, Li L, Tian T, Wang M, Hu Y, Yuan C, Zhang L, Ji C, Ma D. Inactivation of Notch signaling reverses the Th17/Treg imbalance in cells from patients with immune thrombocytopenia. Laboratory Investigation, 2015,1(95):157-167.

27. Zheng M, Yang Q, Heping Z, Yan C, Xinyu Y, Jianguang W. Protectin DX restores Treg/Th17 cell balance in rheumatoid arthritis by inhibiting NLRP3 inflammasome via miR-20a. Cell Death Dis, 2021,12(3):280-291.

\section{Tables}

Table.1 Comparison of serum Notch protein expression of mice in each group

\begin{tabular}{|lllll|}
\hline \multicolumn{1}{|c}{ group } & $\begin{array}{l}\text { model } \\
\text { group }\end{array}$ & $\begin{array}{l}\text { low-dose } \\
\text { Chinese } \\
\text { medicine group }\end{array}$ & $\begin{array}{l}\text { medium-dose } \\
\text { Chinese medicine } \\
\text { group }\end{array}$ & $\begin{array}{l}\text { high-dose } \\
\text { Chinese } \\
\text { medicine group }\end{array}$ \\
\hline Notch(nmol/l) & $9.54 \pm 1.31$ & $5.20 \pm 0.80$ & $5.56 \pm 1.27$ & $5.61 \pm 0.66$ \\
\hline$P \quad$ model group & - & 0.000 & 0.000 & 0.000 \\
\hline $\begin{array}{l}\text { low-dose Chinese } \\
\text { medicine group }\end{array}$ & - & - & 0.629 & 0.577 \\
$\begin{array}{l}\text { medium-dose } \\
\text { Chinese medicine } \\
\text { group }\end{array}$ & - & - & - & 0.939 \\
\hline
\end{tabular}

Table.2 Comparison of key activation protein levels of serum Treg cells in each group of mice 


\begin{tabular}{|c|c|c|c|c|}
\hline $\begin{array}{l}\text { group } \\
\text { Indicator }\end{array}$ & model group & $\begin{array}{l}\text { low-dose } \\
\text { Chinese } \\
\text { medicine group }\end{array}$ & $\begin{array}{l}\text { medium-dose } \\
\text { Chinese } \\
\text { medicine group }\end{array}$ & $\begin{array}{l}\text { high-dose } \\
\text { Chinese } \\
\text { medicine group }\end{array}$ \\
\hline FOX-P3(pg/ml) & $87.09 \pm 12.75$ & $90.68 \pm 25.66$ & $99.62 \pm 26.59$ & $162.89 \pm 59.58$ \\
\hline$P \quad$ model group & - & 0.905 & 0.677 & 0.024 \\
\hline $\begin{array}{l}\text { low-dose } \\
\text { Chinese } \\
\text { medicine group }\end{array}$ & - & - & 0.766 & 0.030 \\
\hline $\begin{array}{l}\text { medium-dose } \\
\text { Chinese } \\
\text { medicine group }\end{array}$ & - & - & - & 0.052 \\
\hline TGF- $\boldsymbol{\beta}(\mathrm{pg} / \mathrm{ml})$ & $3376.47 \pm 350.86$ & $4848.01 \pm 589.75$ & $4906.81 \pm 285.96$ & $4881.01 \pm 661.56$ \\
\hline$P \quad$ model group & - & 0.009 & 0.007 & 0.008 \\
\hline $\begin{array}{l}\text { low-dose } \\
\text { Chinese } \\
\text { medicine group }\end{array}$ & - & - & 0.902 & 0.945 \\
\hline $\begin{array}{l}\text { medium-dose } \\
\text { Chinese } \\
\text { medicine group }\end{array}$ & - & - & - & 0.957 \\
\hline IL-10(pg/ml) & $57.88 \pm 33.13$ & $41.58 \pm 25.29$ & $41.01 \pm 31.46$ & $42.25 \pm 30.39$ \\
\hline$P \quad$ model group & - & 0.511 & 0.497 & 0.529 \\
\hline $\begin{array}{l}\text { low-dose } \\
\text { Chinese } \\
\text { medicine group }\end{array}$ & - & - & 0.982 & 0.978 \\
\hline $\begin{array}{l}\text { medium-dose } \\
\text { Chinese } \\
\text { medicine group }\end{array}$ & - & - & - & 0.960 \\
\hline
\end{tabular}

Table.3 Comparison of key activating protein levels of Th17 cells in serum of mice in each group 


\begin{tabular}{|c|c|c|c|c|}
\hline $\begin{array}{l}\text { group } \\
\text { Indicator }\end{array}$ & model group & $\begin{array}{l}\text { low-dose } \\
\text { Chinese } \\
\text { medicine } \\
\text { group }\end{array}$ & $\begin{array}{l}\text { medium-dose } \\
\text { Chinese } \\
\text { medicine group }\end{array}$ & $\begin{array}{l}\text { high-dose } \\
\text { Chinese } \\
\text { medicine } \\
\text { group }\end{array}$ \\
\hline STAT3(pg/ml) & $89.65 \pm 25.09$ & $53.70 \pm 2.55$ & $57.51 \pm 4.71$ & $49.71 \pm 5.25$ \\
\hline model group & - & 0.003 & 0.006 & 0.001 \\
\hline $\begin{array}{l}\text { low-dose Chinese } \\
\text { medicine group }\end{array}$ & - & - & 0.700 & 0.686 \\
\hline $\begin{array}{l}\text { medium-dose } \\
\text { Chinese medicine } \\
\text { group }\end{array}$ & - & - & - & 0.435 \\
\hline RORyt(ng/ml) & $262.25 \pm 131.97$ & $143.17 \pm 31.62$ & $151.01 \pm 5.65$ & $135.46 \pm 8.29$ \\
\hline$P \quad$ model group & - & 0.024 & 0.032 & 0.017 \\
\hline $\begin{array}{l}\text { low-dose Chinese } \\
\text { medicine group }\end{array}$ & - & - & 0.867 & 0.869 \\
\hline $\begin{array}{l}\text { medium-dose } \\
\text { Chinese medicine } \\
\text { group }\end{array}$ & - & - & - & 0.741 \\
\hline IL-17(pg/ml) & $1159.00 \pm 919.60$ & $657.44 \pm 209.31$ & $663.32 \pm 233.69$ & $481.67 \pm 113.35$ \\
\hline$P \quad$ model group & - & 0.154 & 0.158 & 0.062 \\
\hline $\begin{array}{l}\text { low-dose Chinese } \\
\text { medicine group }\end{array}$ & - & - & 0.986 & 0.603 \\
\hline $\begin{array}{l}\text { medium-dose } \\
\text { Chinese medicine } \\
\text { group }\end{array}$ & - & - & - & 0.592 \\
\hline IL-22(pg/ml) & $332.31 \pm 47.66$ & $44.45 \pm 23.37$ & $44.51 \pm 38.28$ & $75.65 \pm 47.75$ \\
\hline$P \quad$ model group & - & 0.000 & 0.000 & 0.000 \\
\hline $\begin{array}{l}\text { low-dose Chinese } \\
\text { medicine group }\end{array}$ & - & - & 0.999 & 0.373 \\
\hline $\begin{array}{l}\text { medium-dose } \\
\text { Chinese medicine } \\
\text { group }\end{array}$ & - & - & - & 0.374 \\
\hline
\end{tabular}

\section{Figures}




\section{Notch}

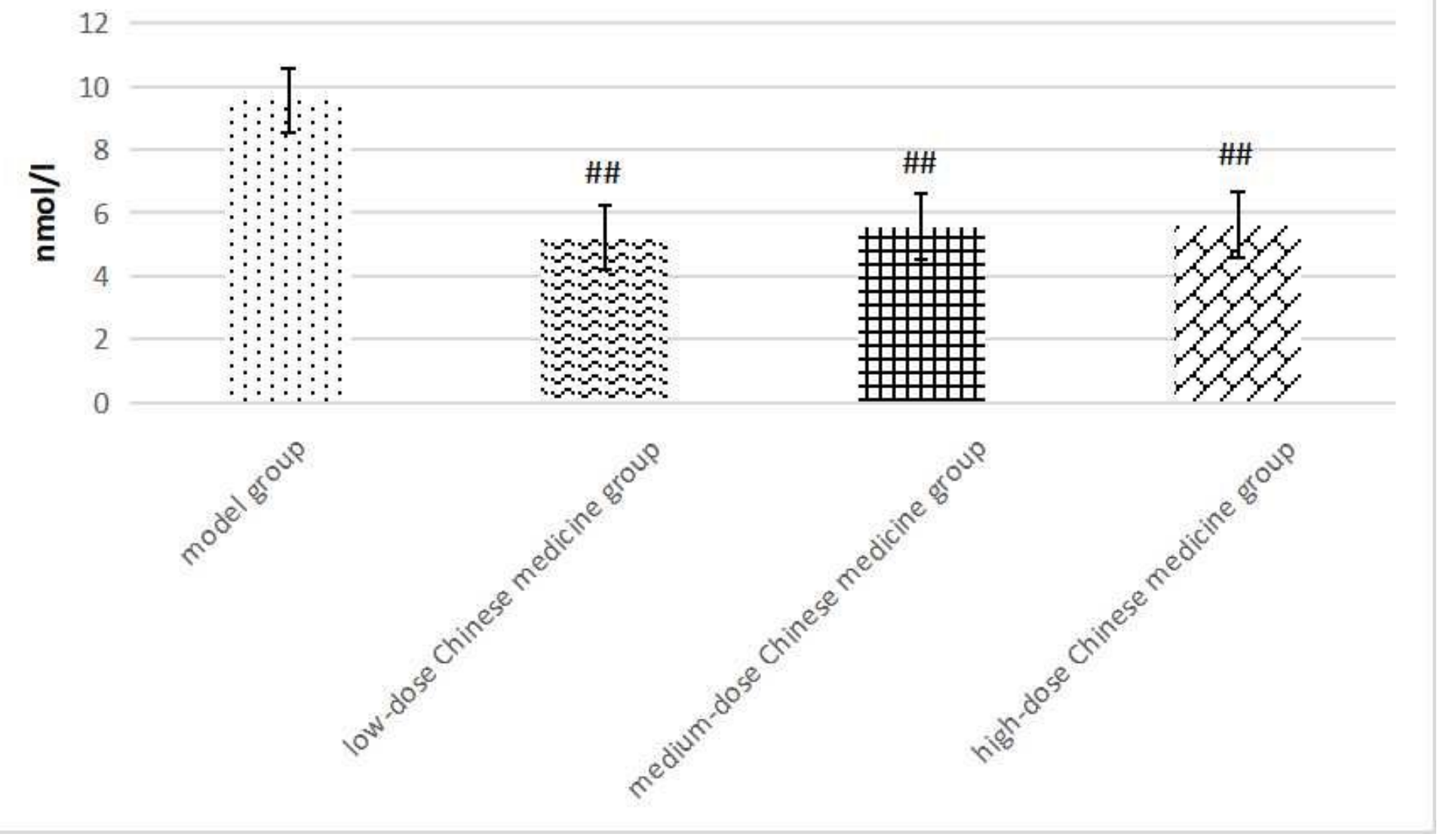

Figure 1

It can be seen from Figure.1 that compared with the model group, the expression of Notch protein in the other groups was significantly reduced, and the difference was statistically significant $(P<0.001)$. 


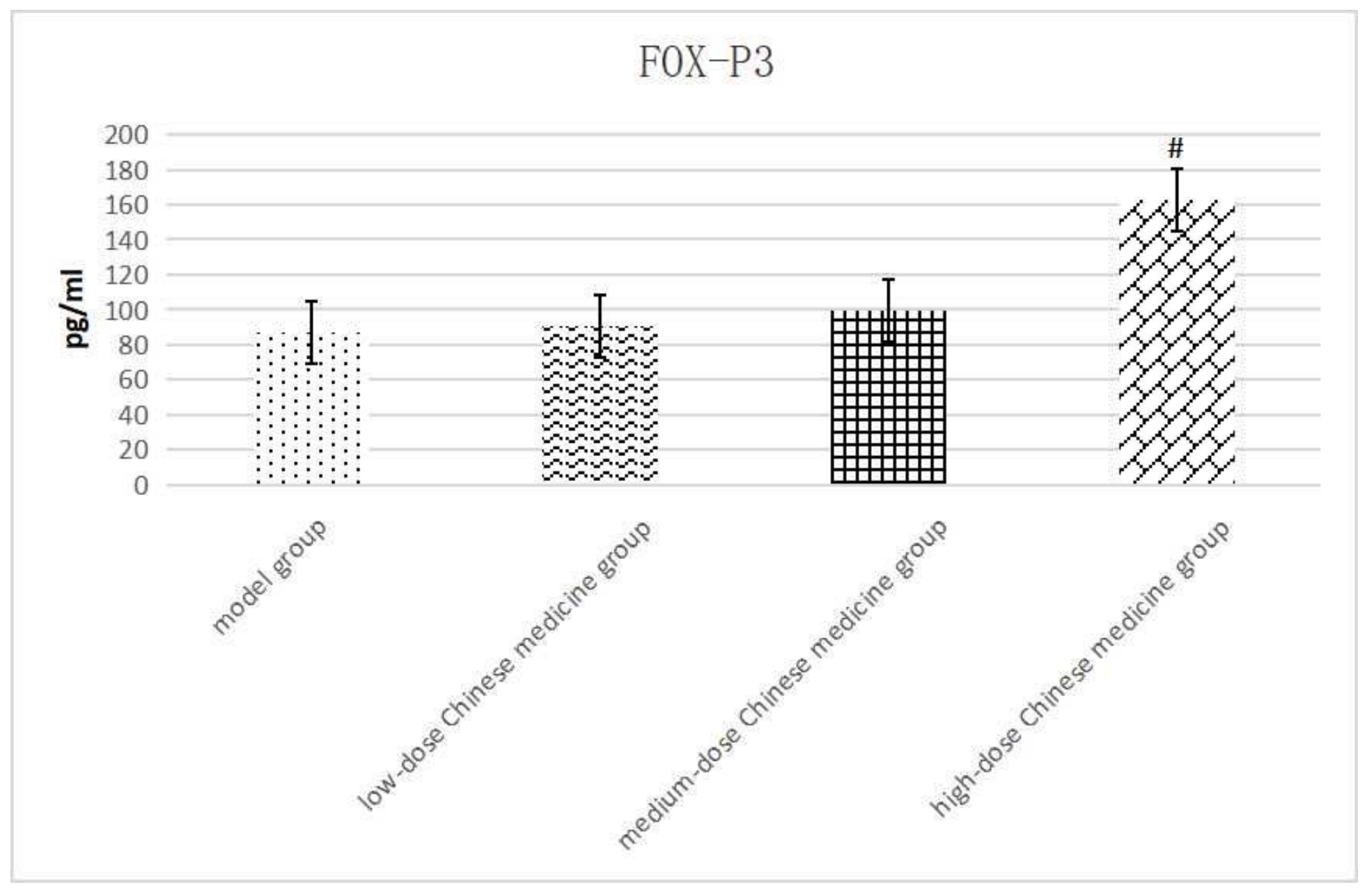

Figure 2

It can be seen from Figure.2 that the serum FOX-P3 level of mice in the high-dose Chinese medicine group was significantly higher than that of the low-dose Chinese medicine group and the model group, and the difference was statistically significant $(P<0.05)$. 


\section{TGF- $\beta$}

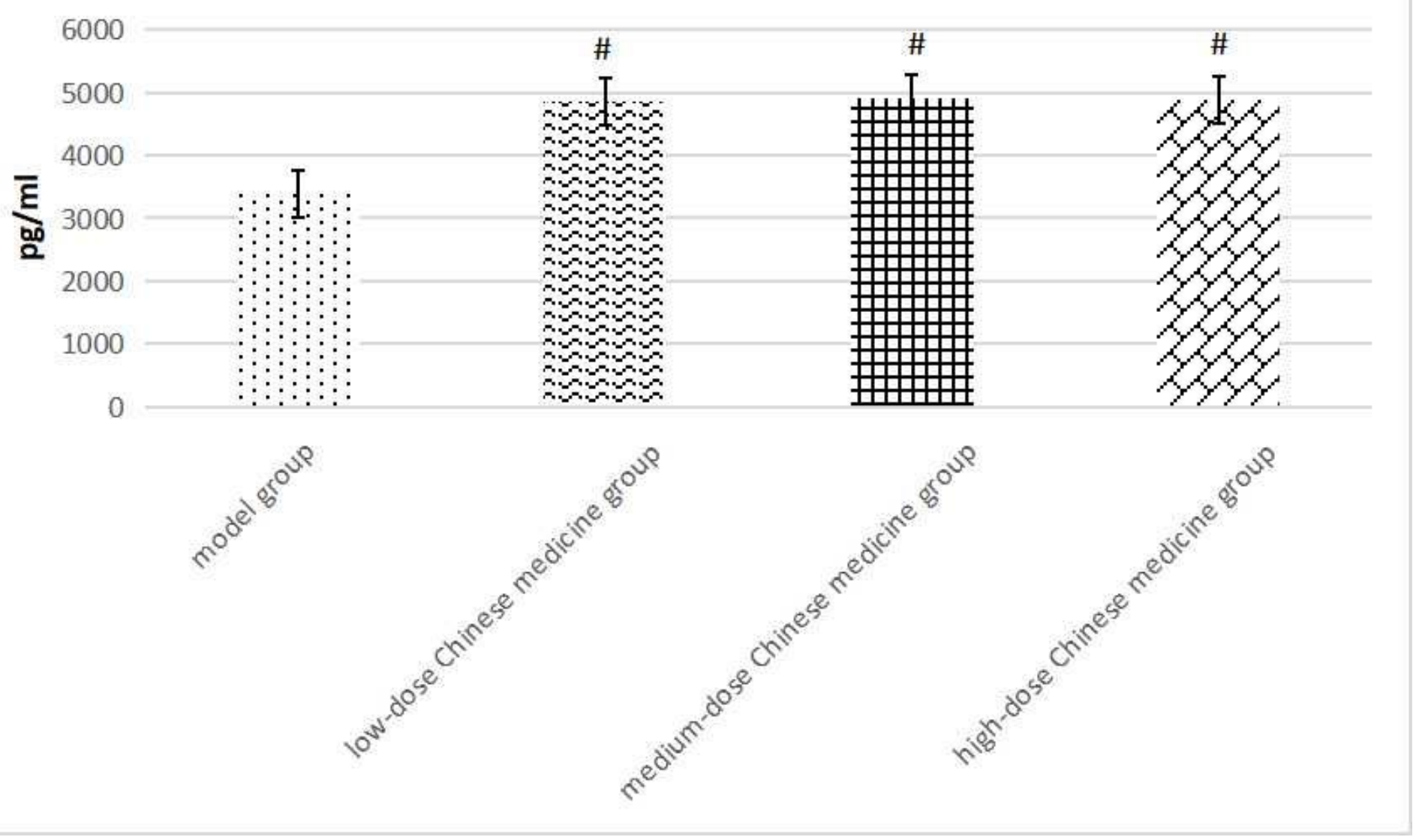

Figure 3

It can be seen from Figure. 3 that compared with the model group, the serum TGF- $\beta$ level of the three groups of traditional Chinese medicine was significantly higher than that of the model group, and the difference was statistically significant $(P<0.05)$. 


\section{IL-10}

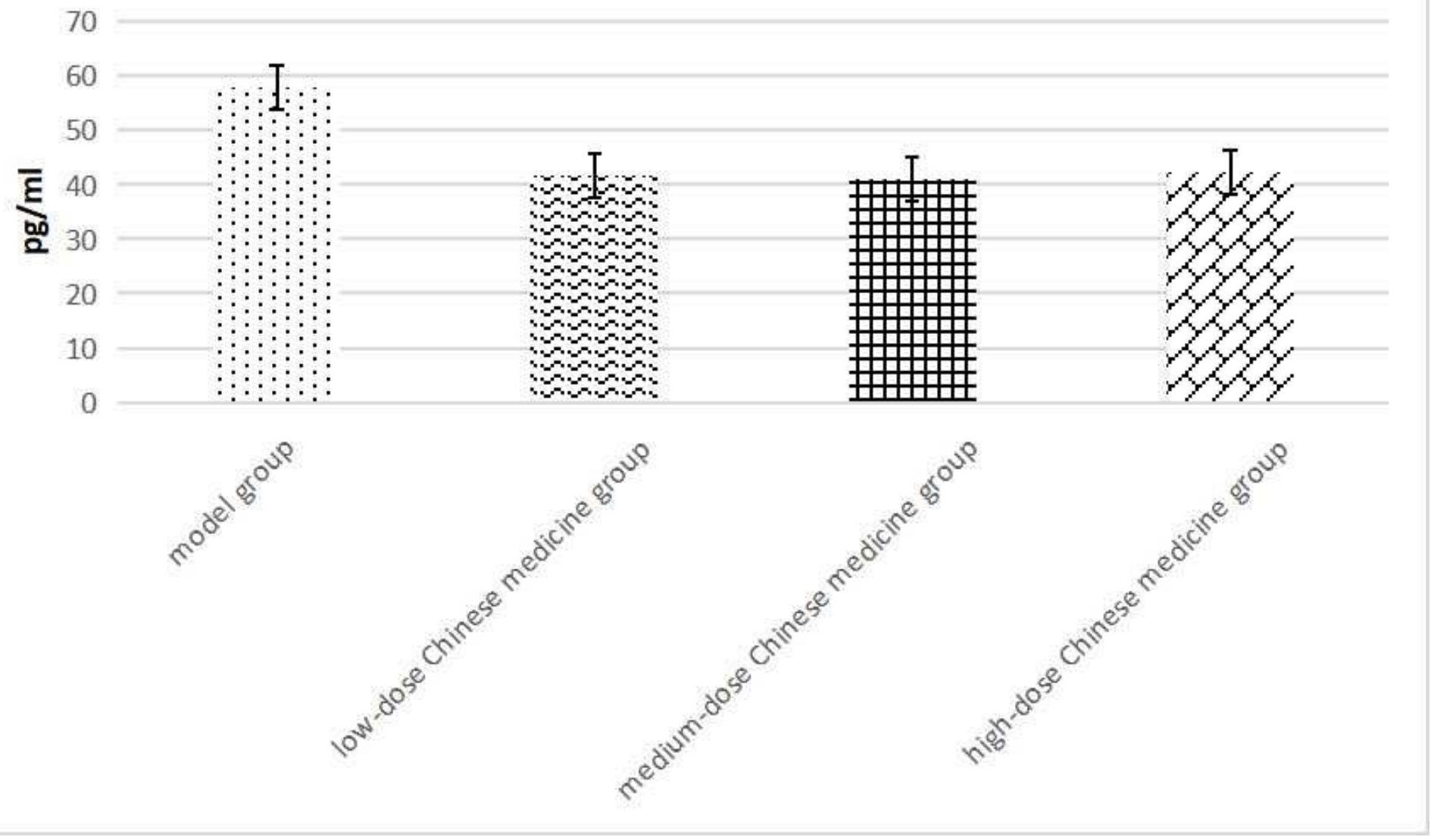

\section{Figure 4}

It can be seen from Figure.4 that there was no statistical difference in the serum IL-10 levels of mice in each group $(P>0.05)$. Compared with the model group, the serum IL-10 levels of mice in the other groups had a downward trend, but the difference was not statistically significant. 


\section{STAT3}

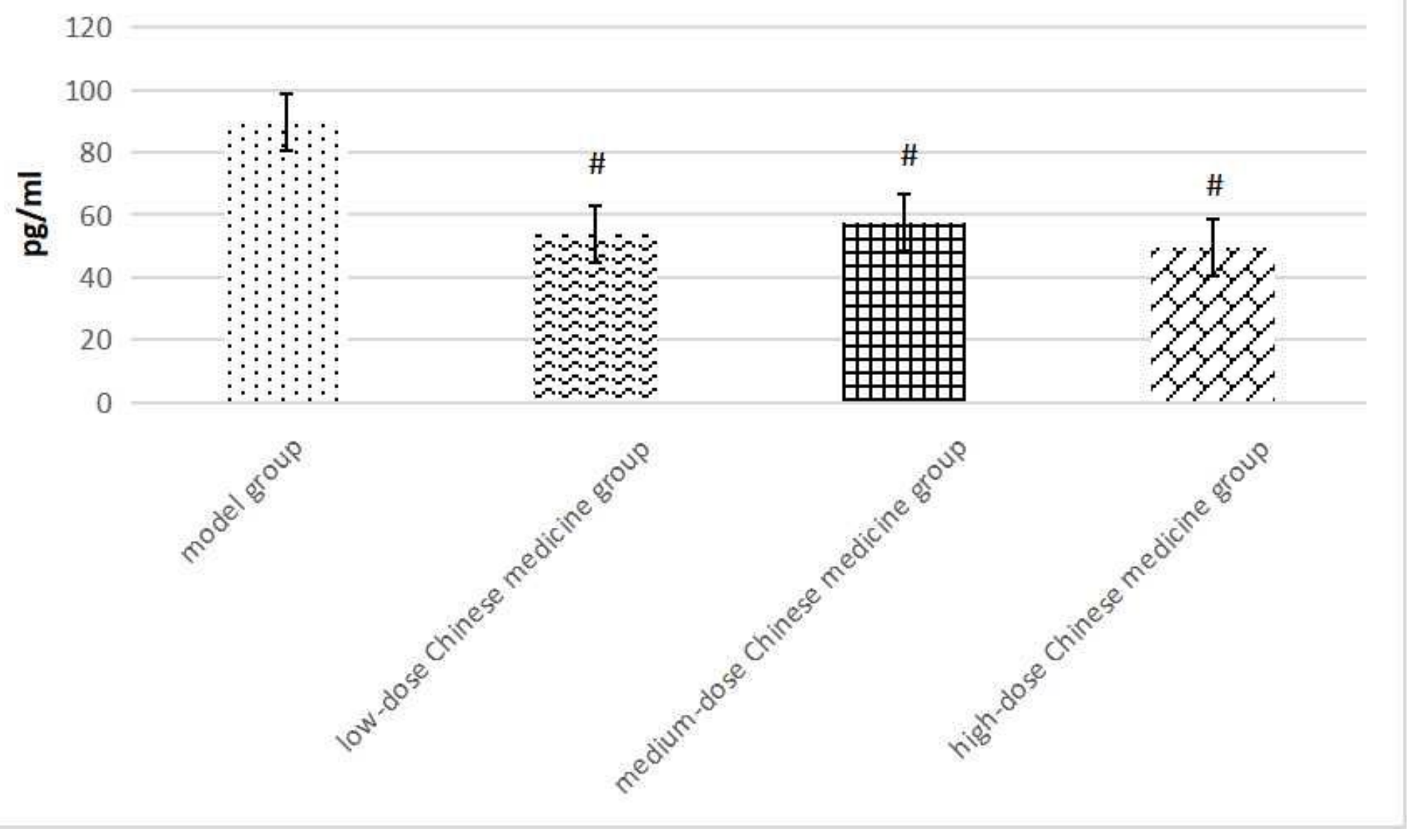

\section{Figure 5}

It can be seen from Figures. 5 that compared with the model group, the serum STAT3 levels of mice in the 3 groups of traditional Chinese medicine decreased significantly, with statistical differences $(P<0.05)$. 


\section{$\operatorname{ROR} \gamma \mathrm{t}$}

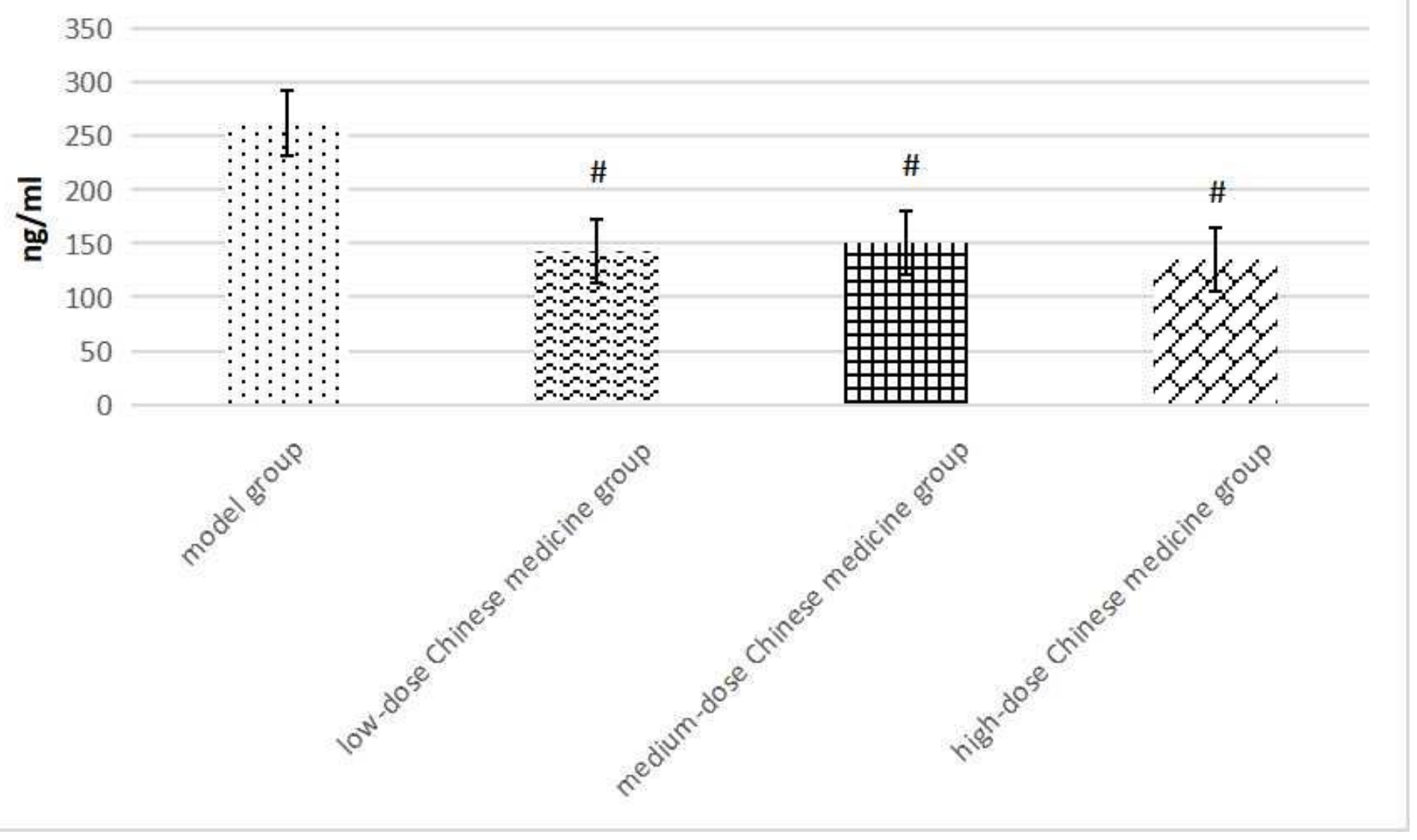

Figure 6

It can be seen from Figures. 6 that compared with the model group, the serum RORyt levels of mice in the 3 groups of traditional Chinese medicine decreased significantly, with statistical differences $(P<0.05)$. 


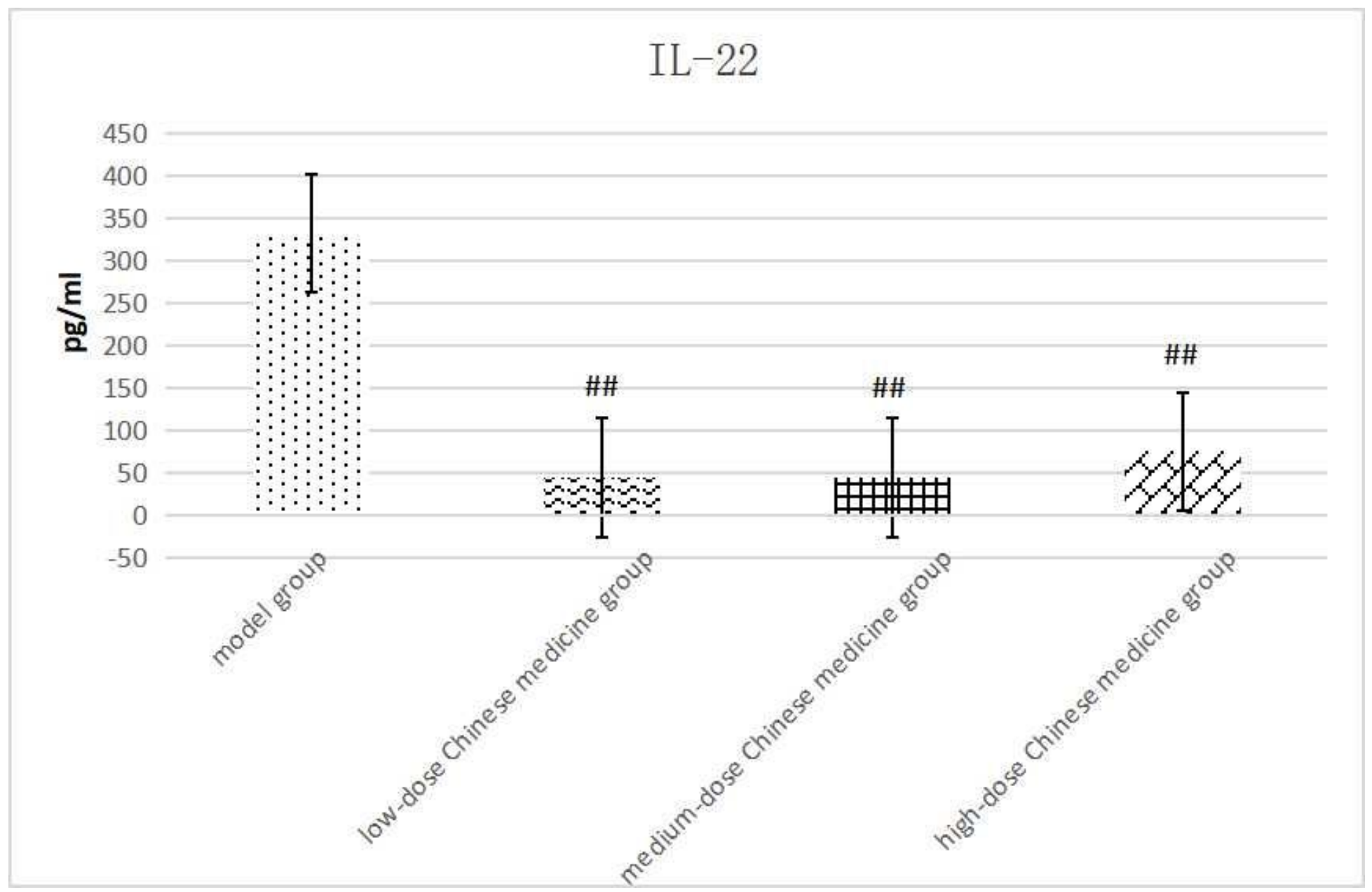

Figure 7

It can be seen from Figures.7 that compared with the model group, the serum IL-22 levels of mice in the 3 groups of traditional Chinese medicine decreased significantly, with statistical differences $(P<0.05)$. 


\section{IL-17}

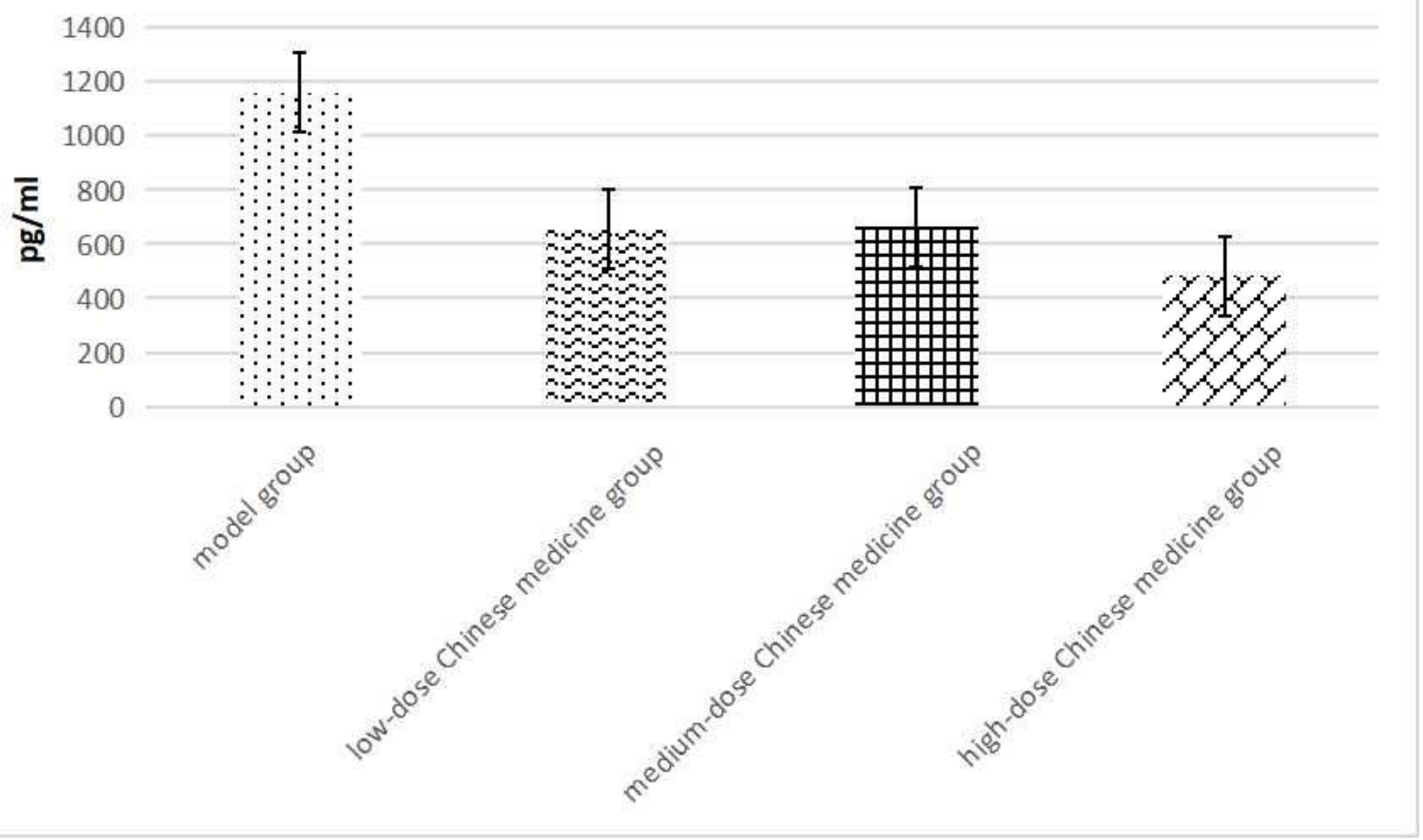

\section{Figure 8}

It can be seen from Figure. 8 that there was no statistical difference in the serum IL-17 levels of mice in each group $(P>0.05)$. Compared with the model group, the serum IL-17 levels of mice in the other groups had a downward trend, but the difference was not statistically significant. 